\title{
Dynamic Time-Delay Characteristics and Structural Optimization Design of Marine Gas Turbine Intercooler
}

\author{
Ning-bo Zhao, ${ }^{1}$ Xue-you Wen, ${ }^{1,2}$ and Shu-ying $\mathrm{Li}^{1}$ \\ ${ }^{1}$ College of Power and Energy Engineering, Harbin Engineering University, Harbin 150001, China \\ ${ }^{2}$ Harbin Marine Boiler and Turbine Research Institute, Harbin 150078, China \\ Correspondence should be addressed to Ning-bo Zhao; zhaoningbo314@126.com
}

Received 14 June 2014; Revised 29 July 2014; Accepted 31 July 2014; Published 28 August 2014

Academic Editor: Gongnan Xie

Copyright (c) 2014 Ning-bo Zhao et al. This is an open access article distributed under the Creative Commons Attribution License, which permits unrestricted use, distribution, and reproduction in any medium, provided the original work is properly cited.

\begin{abstract}
Aiming at the rapid mobility of marine gas turbine and the dynamic time-delay problem of intercooler for intercooled cycle marine gas turbine, the dynamic simulation model of intercooler was set up based on effectiveness-number of transfer units ( $\varepsilon$-NTU) and lumped parameter method in this paper. The model comprehensively considers related physical properties dependent on temperature. Dynamic response characteristics of gas outlet temperature and pressure and coolant outlet temperature of intercooler with different materials and coolants in the change of operation condition of marine gas turbine were analyzed in detail. Besides, this paper explored the use of simulated annealing algorithm for structural optimization of intercooler. The results showed that both material and coolant were the significant factors that affected the heat transfer and dynamic performance of intercooler. The heat transfer and dynamic performance of the intercooler obtained by using simulated annealing algorithm were better than those of preliminary design.
\end{abstract}

\section{Introduction}

In recent years, high-power (more than $25 \mathrm{MW}$ ) marine gas turbine has aroused the attention of every country [1]. Intercooled (IC) cycle or intercooled regenerated (ICR) cycle technology is a feasible method to develop highpower marine gas turbine, which may represent a major development tendency for a new generation of marine main propulsion plants [2]. The successful application of WR21 marine gas turbine further verified the feasibility and effectiveness of intercooled regenerated cycle technology to increase engine power for marine gas turbine [3].

As an important part of intercooled or intercooled regenerated cycle marine gas turbine, intercooler will directly influence the performance of engine. The existence of intercooler can aggravate the time-delay characteristics of fluid flow and heat transfer, which make it difficult to match the thermodynamic parameters and develop appropriate control strategies for gas turbine system, and then may influence the maneuverability performance of ship.
In the past half century, many scholars have carried out extensive research from different aspects and made some achievements of both theory and practice about intercooled or intercooled regenerated cycle gas turbine. The research activities mainly focused on intercooled or intercooled regenerated cycle gas turbine performance analysis [4-10], numerical simulation on flow and heat transfer of intercooler [11-13], and thermodynamic design and optimization of intercooled system [14-16]. Li et al. [4-6] studied the dynamic behaviors and flow parameters optimization of intercooled cycle marine gas turbine based on simulation method. Through the simulation study of fuel supply rate, they obtained the best fuel supply rate curve of intercooled cycle marine gas turbine. Based on the finite time thermodynamic theory, the power and efficiency of an open or closed cycle intercooled gas turbine power plant were analyzed and optimized by adjusting the low pressure compressor inlet relative pressure drop, the mass flow rate, and the distribution of pressure losses along the flow path by Wang et al. [7-10]. According to the actual operation condition of intercooled system for a certain 
intercooled cycle marine gas turbine, Dong et al. [11-13] made a preliminary thermodynamic analysis and design by using effectiveness-number of transfer units ( $\varepsilon$-NTU) method and analyzed the influence of intercooler structural parameters and coolant parameters on the steady-state performance of intercooler. On the base of structure features of plain fin rectangular channels, they also investigated the coupled characteristics of fluid flow and heat transfer by using numerical simulation approach. Through numerical computing, Li et al. [14] and Dong et al. [12] obtained the pressure distribution, temperature distribution, and velocity distribution of intercooler entire flow path, which provided beneficial reference to design and apply intercooler. Xiao [15] discussed the effects of intercooler structure parameters on its flow and heat transfer performance based on effectiveness-number of transfer units ( $\varepsilon$-NTU) method. Then they analyzed the dynamic performance and thermal inertia of intercooler under varying operation conditions. Their research results showed that intercooler had the obvious thermal inertia characteristics, which could directly affect the accuracy and reliability of the control system. Besides, Zhang [16] established the dynamic simulation model by using the lumped parameter method and analyzed the dynamic response of gas outlet temperature of intercooler under varying operation conditions. Their conclusions were consistent with the results that have been reported in literature [15]. They also found that heat exchanger weight had a significant influence on the dynamic performance of intercooler.

From the literatures described above, very few studies have been performed on the thorough discussion of relevant factors that could affect the dynamic time-delay characteristics of intercooler. There were also very few studies which discussed the structural optimization design of intercooler using artificial intelligent algorithm. Besides, the dynamic simulation analyses in the existing literatures only considered the change of gas inlet temperature of intercooler, which belonged to the single variable perturbation analysis. However, all the gas inlet temperature, pressure, and mass flow rate of intercooler will change in practical applications. Therefore, it is meaningful to study the dynamic behaviors of intercooler with multivariable perturbation.

The objectives of this study are to investigate the flow and heat transfer coupling dynamic time-delay problem and structural optimization design of intercooler for intercooled cycle marine gas turbine. In this study, the dynamic simulation model of intercooler is modeled based on effectivenessnumber of transfer units ( $\varepsilon$-NTU) and lumped parameter method. In order to improve the modeling accuracy, temperature dependent thermophysical properties are taken into account due to large temperature differences in the intercooler. Then, three different types of substrate materials (copper, alumina, and copper-nickel alloy) and two different coolants (water and ethylene glycol) are considered to investigate the effect of substrate materials and coolants on dynamic performance of intercooler in detail. Finally, a simulated annealing (SA) algorithm based optimization technique for intercooler will be developed, which minimizes the total weight of intercooler under given space and performance restrictions.

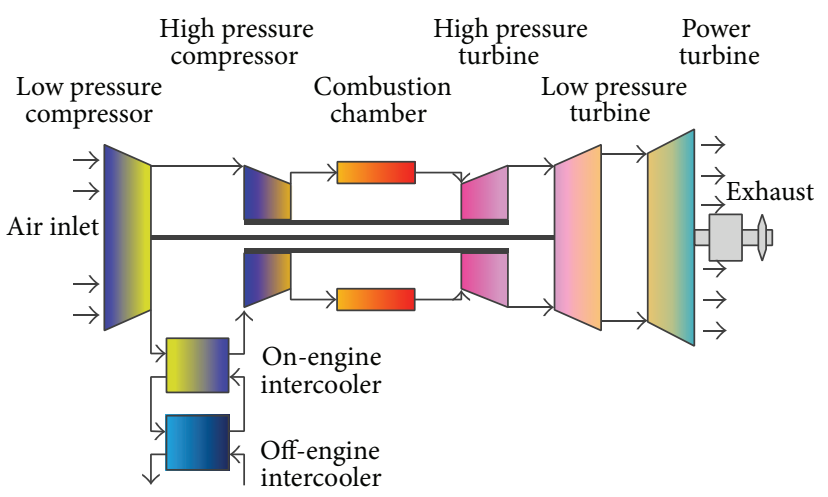

FIGURE 1: Principle diagram of intercooled cycle marine gas turbine.

\section{Intercooler Problem Description and Thermodynamic Model}

2.1. Problem Description of Intercooled System. As the key component, intercooled system is located between the low pressure compressor and high pressure compressor. The intercooler system lowers the high pressure compressor inlet temperature, which can reduce the power consumption of high pressure compressor and increase the power output of the whole marine gas turbine system.

The principle diagram of intercooled cycle marine gas turbine is shown in Figure 1. Intercooler system is composed of two parts, namely, on-engine intercooler (platefin heat exchanger) and off-engine intercooler (plate heat exchanger). The on-engine intercooler is designed to decrease the temperature of the pressurized gas coming out of the low pressure compressor. Then the coolant passes through offengine intercooler, which transfers heat from the coolant to the seawater in order to reduce the temperature of coolant. Compared with off-engine intercooler, on-engine intercooler is more important for marine gas turbine because it has a direct influence on the gas turbine performance.

According to the requirements of intercooled cycle, three performance parameters should be considered for on-engine intercooler. (1) Reasonable pressure drop of the fluid (especially for gas), including the pressure drop of inlet channels, core part, and outlet channels. When the pressure drop of gas is too high, it will give an additional burden on the high pressure compressor to keep a constant pressure ratio, which means more fuel consumption. (2) Reasonable thermal efficiency of intercooler, which can effectively lower outlet temperature of gas under given space. (3) Reasonable weight of intercooler. There may have a greater thermal inertia when the weight is heavier. Therefore, how to realize the optimization design of high efficiency compact intercooler is one of the important problems for intercooled system.

Due to the complexity in the structure of the intercooler, the detailed information of the fluid flow and heat transfer in intercooler can scarcely be described. Different substrate materials and coolants have different heat transfer performance, which can influence the flow and heat transfer performance of intercooler. So the effects of different materials and 


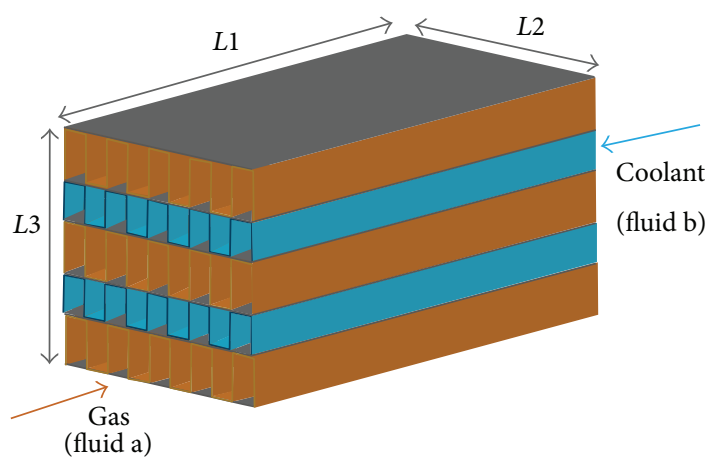

FIGURE 2: Schematic representation of reverse flow plate-fin intercooler.

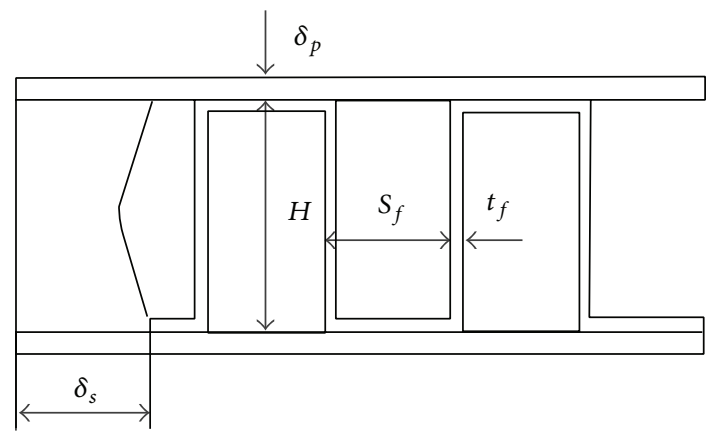

FIGURE 3: Detailed view of straight fin.

coolants on dynamic performance of intercooler are worth studying in detail.

2.2. Thermal Modeling of Intercooler. Figures 2 and 3 depict a schematic view of a reverse flow plate-fin intercooler with straight fins and the basic geometric structure of fins, respectively. The following assumptions will be used for the analysis.

(1) The number of fin layers for the gas side $\left(N_{a}\right)$ is assumed to be one more than the coolant side $\left(N_{b}\right)$. That is, $N_{a}=N_{b}+1$.

(2) Intercooler works in a steady-state condition.

(3) The thickness of all the fins is assumed uniform and the thermal resistance can be negligible because the thickness is too small.

(4) All the parts are made of same material.

(5) The influences of fouling and corrosion are neglected.

In this study, since the output temperature of the fluids is unspecified, the $\varepsilon$-NTU method is used to assess the flow and heat transfer performance of intercooler in the modeling process. The effectiveness of reverse flow plate-fin intercooler is proposed as

$$
\varepsilon=\frac{1-\exp [-\mathrm{NTU}(1-\mathrm{Cr})]}{1-\mathrm{Cr} \exp [-\mathrm{NTU}(1-\mathrm{Cr})]},
$$

where $\mathrm{Cr}=C_{\min } / C_{\max }$ is heat capacity ratio. NTU is the number of transfer units. Considering the thermal resistance of the walls, NTU can be determined by

$$
\begin{gathered}
\frac{1}{\mathrm{NTU}}=\frac{C_{\min }}{U A}, \\
\frac{1}{U A}=\frac{1}{\eta_{\mathrm{ef}, a} h_{a} A_{a}}+\frac{\delta_{p}}{\lambda_{p} A_{p}}+\frac{1}{\eta_{\mathrm{ef}, b} h_{b} A_{b}} .
\end{gathered}
$$

Generally, the flow state of fluids can affect the convective heat transfer coefficient. For the fluids in the fully developed turbulent flow and transition region, the heat transfer coefficient is calculated in terms of Gnielinski [18] which is given as

$$
h=\frac{\mathrm{Nu} \lambda}{\mathrm{D}} .
$$

Nusselt number and hydraulic diameter can be calculated as follows:

$$
\begin{gathered}
\mathrm{Nu}=\frac{(f / 2)(\operatorname{Re}-1000) \operatorname{Pr}}{1+12.7(f / 2)^{0.5}\left(\operatorname{Pr}^{2 / 3}-1\right)}, \\
D=\frac{2\left(H-t_{f}\right)\left(S_{f}-t_{f}\right)}{H+S_{f}-2 t_{f}} .
\end{gathered}
$$
below:

Reynolds number and Prandtl number are defined as

$$
\begin{aligned}
& \operatorname{Re}=\frac{\rho u D}{\mu}, \\
& \operatorname{Pr}=\frac{C_{p} \mu}{\lambda} .
\end{aligned}
$$

And the Fanning factor $f$ is given as

$$
f=\frac{1}{(1.58 \ln \operatorname{Re}-3.28)^{2}} .
$$

For the fluids in the fully developed laminar flow, the heat transfer coefficient is calculated in terms of Colburn factor $[19,20]$ which is given as

$$
h=\frac{j G C_{p}}{\operatorname{Pr}^{2 / 3}} .
$$

Mass flow velocity can be obtained as follows:

$$
G=\frac{W}{A_{\mathrm{ff}}} .
$$

The Fanning factor $f$ and Colburn factor $j$ are given as

$$
\begin{gathered}
f=\exp \left[0.106566(\ln R e)^{2}-2.12158(\ln R e)+5.82505\right], \\
j=\exp \left[0.103109(\ln R e)^{2}-1.91091(\ln R e)+3.211\right] .
\end{gathered}
$$


In this study, the effective circulation area for the two sides is formulated as

$$
\begin{aligned}
A_{\mathrm{ff}, a} & =\frac{N_{a}\left(L 2-2 \delta_{s}\right)\left(H_{a}-t_{f, a}\right)\left(S_{f, a}-t_{f, a}\right)}{S_{f, a}}, \\
A_{\mathrm{ff}, b} & =\frac{N_{b}\left(L 2-2 \delta_{s}\right)\left(H_{b}-t_{f, b}\right)\left(S_{f, b}-t_{f, b}\right)}{S_{f, b}} .
\end{aligned}
$$

The heat transfer areas of intercooler for the two sides are calculated by

$$
\begin{aligned}
& A_{a}=2 N_{a} L 1\left(L 2-2 \delta_{s}\right)\left[1+\frac{\left(H_{a}-2 t_{f, a}\right)}{S_{f, a}}\right], \\
& A_{b}=2 N_{b} L 1\left(L 2-2 \delta_{s}\right)\left[1+\frac{\left(H_{b}-2 t_{f, b}\right)}{S_{f, b}}\right] .
\end{aligned}
$$

Heat transfer efficiencies of heat transfer surface for the two sides are obtained by

$$
\begin{aligned}
& \eta_{\mathrm{ef}, a}=\frac{\left(s_{f, a}-t_{f, a}\right)+\eta_{f, a}\left(H_{a}-t_{f, a}\right)}{S_{f, a}+H_{a}-2 t_{f, a}}, \\
& \eta_{\mathrm{ef}, b}=\frac{\left(s_{f, b}-t_{f, b}\right)+\eta_{f, b}\left(H_{b}-t_{f, b}\right)}{S_{f, b}+H_{b}-2 t_{f, b}} .
\end{aligned}
$$

Heat transfer efficiencies of fin for the two sides are formulated as

$$
\begin{aligned}
\eta_{f, a} & =\frac{\tan \left(0.5 m_{a} H_{a}\right)}{0.5 m_{a} H_{a}}, \\
\eta_{f, b} & =\frac{\tan \left(0.5 m_{b} H_{b}\right)}{0.5 m_{b} H_{b}} .
\end{aligned}
$$

Fin factors for the two sides are defined as follows:

$$
\begin{aligned}
& m_{a}=\sqrt{\frac{2 h_{a}}{\lambda_{f, a} t_{f, a}}}, \\
& m_{b}=\sqrt{\frac{2 h_{b}}{\lambda_{f, b} t_{f, b}}} .
\end{aligned}
$$

Therefore, the effective heat transfer area for the two sides can be calculated by

$$
\begin{aligned}
& A_{\mathrm{ef}, a}=2 N_{a} L 1\left(L 2-2 \delta_{s}\right)\left[\frac{\left(S_{f, a}-t_{f, a}\right)+\eta_{f, a}\left(H_{a}-t_{f, a}\right)}{S_{f, a}}\right], \\
& A_{\mathrm{ef}, b}=2 N_{b} L 1\left(L 2-2 \delta_{s}\right)\left[\frac{\left(S_{f, b}-t_{f, b}\right)+\eta_{f, b}\left(H_{b}-t_{f, b}\right)}{S_{f, b}}\right] .
\end{aligned}
$$

Heat transfer rate is obtained as follows:

$$
\mathrm{Q}=\varepsilon C_{\min }\left(T_{\mathrm{in}, a}-T_{\mathrm{in}, b}\right) .
$$

To simplify the computation, this study only considers the pressure drop of inlet channels, core part, and outlet channels. The total pressure drops for every side are defined as below:

$$
\Delta P=\Delta P_{1}-\Delta P_{2}+\Delta P_{3},
$$

where $\Delta P_{1}$ is the pressure drop caused by the change of crosssectional area from the deflector outlet to fin inlet. $\Delta P_{2}$ is the pressure drop caused by the change of cross-sectional area from fin inlet to deflector outlet. $\Delta P_{3}$ consists of two pressure drops, namely, frictional pressure drops and pressure drops, caused by change of channel area. They can be determined as follows:

$$
\begin{gathered}
\Delta P_{1}=\frac{G^{2}}{2 \rho_{\text {in }}}\left(1-\alpha^{2}+K_{\text {in }}\right), \\
\Delta P_{2}=\frac{G^{2}}{2 \rho_{\text {out }}}\left(1-\alpha^{2}-K_{\text {out }}\right), \\
\Delta P_{3}=\frac{G^{2}}{2 \rho_{\text {in }}}\left[2\left(\frac{\rho_{\text {in }}}{\rho_{\text {out }}}-1\right)+\left(\frac{4 f L 1}{D}\right) \frac{\rho_{\text {in }}}{\bar{\rho}}\right],
\end{gathered}
$$

where $K_{\text {in }}$ and $K_{\text {out }}$ are empirical coefficient and can be obtained from literature [21]. $\bar{\rho}$ is the average density of fluids, which is calculated by

$$
\bar{\rho}=\frac{\rho_{\text {in }}+\rho_{\text {out }}}{2} .
$$

Therefore, the pressure drop loss rate of fluids for the two sides is obtained by

$$
\begin{aligned}
& \gamma_{a}=\frac{\Delta P_{a}}{P_{\text {in }, a}}, \\
& \gamma_{b}=\frac{\Delta P_{b}}{P_{\text {in }, b}} .
\end{aligned}
$$

2.3. Dynamic Simulation Modeling of Intercooler. The dynamic time-delay of intercooler is one important factor that influences the maneuverability of marine gas turbine. Considering the operation characteristics of intercooler in practical application, lumped parameter model is used to construct the dynamic simulation model of intercooler. The following assumptions will be used for the analysis.

(1) The inside flow of fin channel is simplified as the one dimension and the velocity of fluids is uniform in the same section.

(2) The temperature of metal wall varies along with the direction of fluids flow and the radial temperature difference of metal wall is neglected.

(3) The heat capacity of gas is neglected compared with that of metal wall.

Considering the above assumptions, the mass conservation equations for the two sides can be given as

$$
\begin{aligned}
& W_{\text {in }, a}=W_{\text {out }, a}, \\
& W_{\text {in }, b}=W_{\text {out }, b} .
\end{aligned}
$$


And the energy conservation equations for the two sides are formulated as

$$
\begin{aligned}
& V_{a} \frac{d}{d t}\left(\rho_{m, a} C_{p, m, a} T_{m, a}\right) \\
&= W_{\text {in }, a} C_{p, \text { in }, a} T_{\text {in }, a}-W_{\text {out }, a} C_{p, \text { out }, a} T_{\text {out }, a} \\
& \quad-h_{a} A_{\text {ef }, a}\left(T_{m, a}-T_{w}\right), \\
& V_{b} \frac{d}{d t}\left(\rho_{m, b} C_{p, m, b} T_{m, b}\right) \\
&=W_{\text {in }, b} C_{p, \text { in }, b} T_{\text {in }, b}-W_{\text {out }, b} C_{p, \text { out }, b} T_{\text {out }, b} \\
& \quad+h_{b} A_{\text {ef }, b}\left(T_{w}-T_{m, b}\right),
\end{aligned}
$$

where $T_{m, a}$ and $T_{m, b}$ are the average temperature for the two sides and are calculated by

$$
\begin{aligned}
T_{m, a} & =\frac{T_{\mathrm{in}, a}+T_{\mathrm{out}, a}}{2}, \\
T_{m, b} & =\frac{T_{\mathrm{in}, b}+T_{\mathrm{out}, b}}{2} .
\end{aligned}
$$

The channel volumes for the two sides are obtained by

$$
\begin{aligned}
& V_{a}=\frac{\left(H_{a}-t_{f, a}\right)\left(S_{f, a}-t_{f, a}\right) L 1 N_{a}\left(L 2-2 \delta_{s}\right)}{S_{f, a}}, \\
& V_{b}=\frac{\left(H_{b}-t_{f, b}\right)\left(S_{f, b}-t_{f, b}\right) L 1 N_{b}\left(L 2-2 \delta_{s}\right)}{S_{f, b}} .
\end{aligned}
$$

The temperature of metal wall is obtained as follows:

$$
M_{w} C_{p, w} \frac{d}{d t} T_{w}=h_{a} A_{\mathrm{ef}, a}\left[T_{m, a}-T_{w}\right]-h_{b} A_{\mathrm{ef}, b}\left[T_{w}-T_{m, b}\right] .
$$

In order to further raise the precision of simulation, the model considers related physical properties dependent on temperature.

\section{Dynamic Performance Analysis and Discussions for Intercooler}

Based on effectiveness-number of transfer units ( $\varepsilon$-NTU) and lumped parameter method mentioned earlier, the dynamic simulation model of intercooler is established by computer simulation software MATLAB/SIMULINK, which can be seen in Figure 4.

3.1. Model Validation. In order to verify the correctness and validity of the simulation model established in this paper, a case study taken from the work of Wen is considered [17]. The straight fin is used on the gas and coolant side. The preliminary structure of the intercooler is shown in Table 1. Table 2 lists the inlet parameters of gas under different gas turbine operation conditions. Water is chosen as the coolant and its inlet temperature and mass flow are assumed to be
TABLE 1: Preliminary structure of the intercooler [17].

\begin{tabular}{lc}
\hline Parameters & Values \\
\hline Number of gas side fin layers, $N_{a}$ & 36 \\
Fin pitch of gas side, $S_{f, a}(\mathrm{~m})$ & $1.4 \times 10^{-3}$ \\
Plate pitch of gas side, $H_{a}(\mathrm{~m})$ & $6.2 \times 10^{-3}$ \\
Fin thickness of gas side, $t_{f, a}(\mathrm{~m})$ & $2 \times 10^{-4}$ \\
Number of coolant side fin layers, $N_{b}$ & 35 \\
Fin pitch of coolant side, $S_{f, b}(\mathrm{~m})$ & $1.4 \times 10^{-3}$ \\
Plate pitch of coolant side, $H_{b}(\mathrm{~m})$ & $3 \times 10^{-3}$ \\
Fin thickness of coolant side, $t_{f, b}(\mathrm{~m})$ & $2 \times 10^{-4}$ \\
Side plate thickness, $\delta_{\text {sp }}(\mathrm{m})$ & $1.6 \times 10^{-3}$ \\
Plate thickness, $\delta_{p}(\mathrm{~m})$ & $5 \times 10^{-4}$ \\
Seal thickness, $\delta_{s}(\mathrm{~m})$ & $6 \times 10^{-3}$ \\
Intercooler length, $L 1(\mathrm{~m})$ & 0.35 \\
Intercooler width, $L 2(\mathrm{~m})$ & 0.4266 \\
\hline
\end{tabular}

TABLE 2: The inlet parameters of gas under different gas turbine operation conditions [17].

\begin{tabular}{lccc}
\hline $\begin{array}{l}\text { Operation } \\
\text { conditions }\end{array}$ & $\begin{array}{c}\text { Inlet pressure } \\
(\mathrm{Pa})\end{array}$ & $\begin{array}{c}\text { Inlet temperature } \\
\left({ }^{\circ} \mathrm{C}\right)\end{array}$ & $\begin{array}{c}\text { Inlet mass } \\
\text { flow }(\mathrm{kg} / \mathrm{s})\end{array}$ \\
\hline $100 \%$ & 302963 & 155.25 & 72.93 \\
$85 \%$ & 288460 & 149.45 & 68.52 \\
$70 \%$ & 277647 & 143.55 & 64.10 \\
$58 \%$ & 258919 & 135.45 & 57.36 \\
$47 \%$ & 240192 & 127.35 & 50.63 \\
$35 \%$ & 221464 & 119.25 & 43.89 \\
$17 \%$ & 170000 & 107.25 & 32.90 \\
\hline
\end{tabular}

TABLE 3: Thermophysical parameters of different materials.

\begin{tabular}{lccc}
\hline Material type & $\begin{array}{c}\text { Thermal } \\
\text { conductivity } \\
(\mathrm{W} / \mathrm{m} \cdot \mathrm{K})\end{array}$ & $\begin{array}{c}\text { Specific heat } \\
\text { capacity } \\
(\mathrm{J} / \mathrm{kg} \cdot \mathrm{K})\end{array}$ & $\begin{array}{c}\text { Density } \\
\left(\mathrm{kg} / \mathrm{m}^{3}\right)\end{array}$ \\
\hline Copper-nickel alloy & 38.5 & 380 & 8890 \\
Copper & 401 & 386 & 8960 \\
Aluminum & 237 & 897 & 2700 \\
\hline
\end{tabular}

constant under different gas turbine operation conditions, which are $20^{\circ} \mathrm{C}$ and $200 \mathrm{~kg} / \mathrm{s}$, respectively. The intercooler is made of copper-nickel alloy. Some useful thermophysical parameters of copper-nickel alloy are mentioned in Table 3.

Figures 5, 6, and 7 show the comparisons of the simulation results in this paper with the thermodynamic calculation and numerical simulation results that have been reported in literature [17]. From Figures 5-7, it is obvious that the outlet temperature and pressure drop loss rate of gas and outlet temperature of coolant obtained by using the simulation model (variable properties) are basically consistent with the thermodynamic calculation results reported in literature [17]. The maximum deviation of pressure drop loss rate of gas is about $0.8 \%$ between simulation model (variable properties) and thermodynamic calculation method. In other words, the simulation model (variable properties) can be 


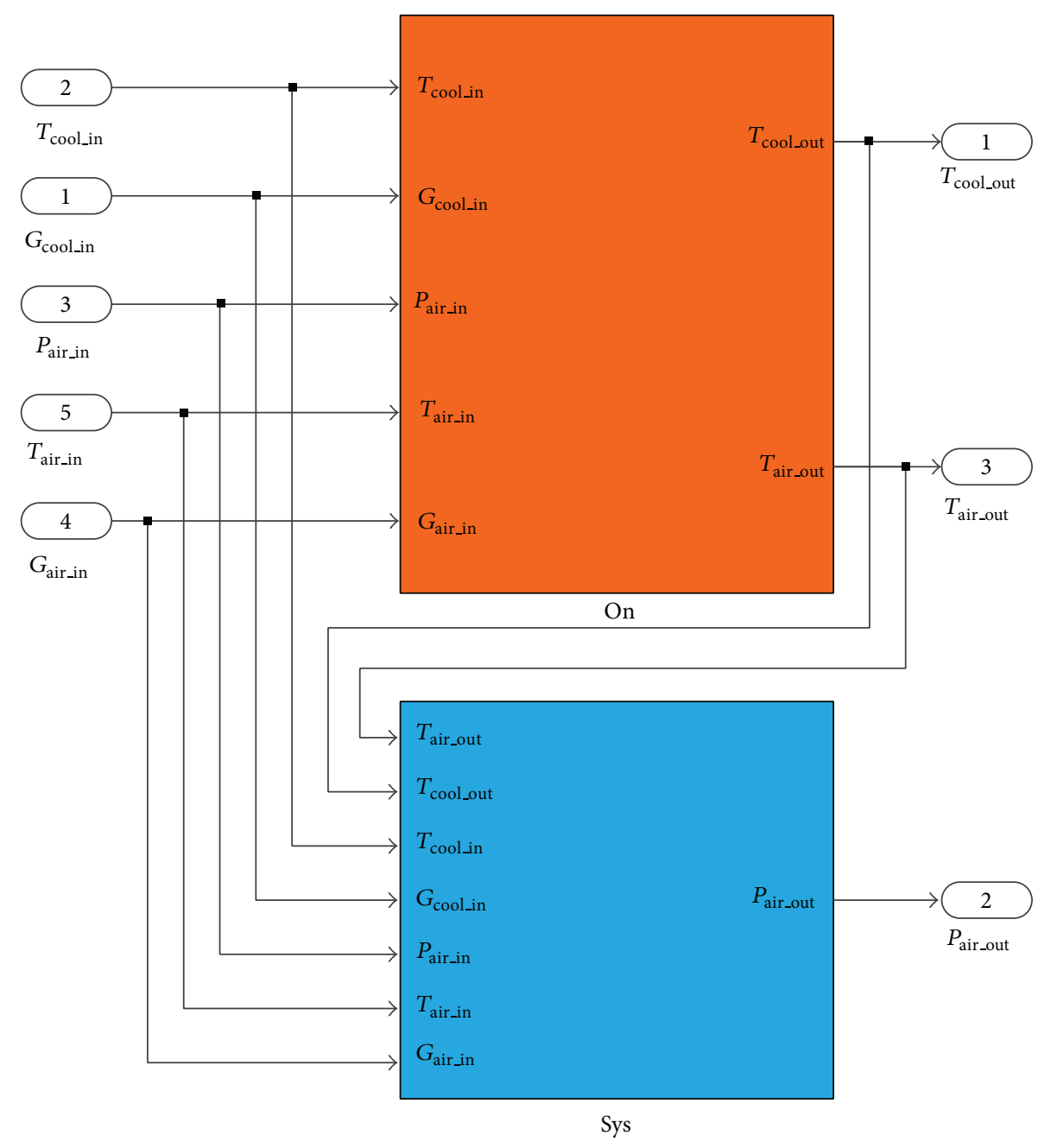

Figure 4: Dynamic simulation model of intercooler.

considered correct and feasible. The simulation results also show that both the outlet temperatures of gas and coolant can decrease when the operation conditions of gas turbine are reduced. In addition, the analysis and comparisons of the results demonstrate that the pressure drop loss rate of gas obtained by using the numerical simulation method is lower than that calculated by using other two methods at some operation conditions. The reason is that only the flow resistance loss of gas side is considered during the numerical simulation processes. Comparing the results obtained by two simulation models in this paper with those of literature [17], we also can conclude that the simulation model (variable properties) is more accurate and appropriate. Moreover, the convergence speed can be significantly improved when considering the influence of temperature on thermal physical property parameters. Therefore, the simulation model (variable properties) is used to analyze and discuss the dynamic performance of intercooler in the following section.

3.2. Material Effects on Dynamic Performance. Material is one of the important factors which affect the structural strength and heat transfer performance of intercooler. In the following analysis, we will focus on investigating the effects of different material on dynamic performance of intercooler. The geometric dimensions of the intercooler and the thermophysical properties of materials (copper-nickel alloy, copper, and aluminum) studied here are listed in Tables 1 and 3. Water is chosen as the coolant and its inlet temperature and mass flow are assumed to be constant under different gas turbine operation conditions, which are $20^{\circ} \mathrm{C}$ and $200 \mathrm{~kg} / \mathrm{s}$, respectively. For the gas turbine, the operation condition linearly changes from $35 \%$ to $70 \%$ in 5 seconds and the related inlet operation parameters of gas are given in Table 2.

The dynamic response curve of the outlet temperature and pressure of gas and the outlet temperature of coolant with different materials in the change of operation condition of gas turbine are shown in Figures 8, 9, and 10. It may be clearly observed in Figures 8-10 that the outlet temperatures of gas and coolant change obviously in the previous stages and their gradients become smaller over time for all materials. The thermal inertia characteristic of intercooler is so obvious that it is necessary to consider the effect of intercooler on 


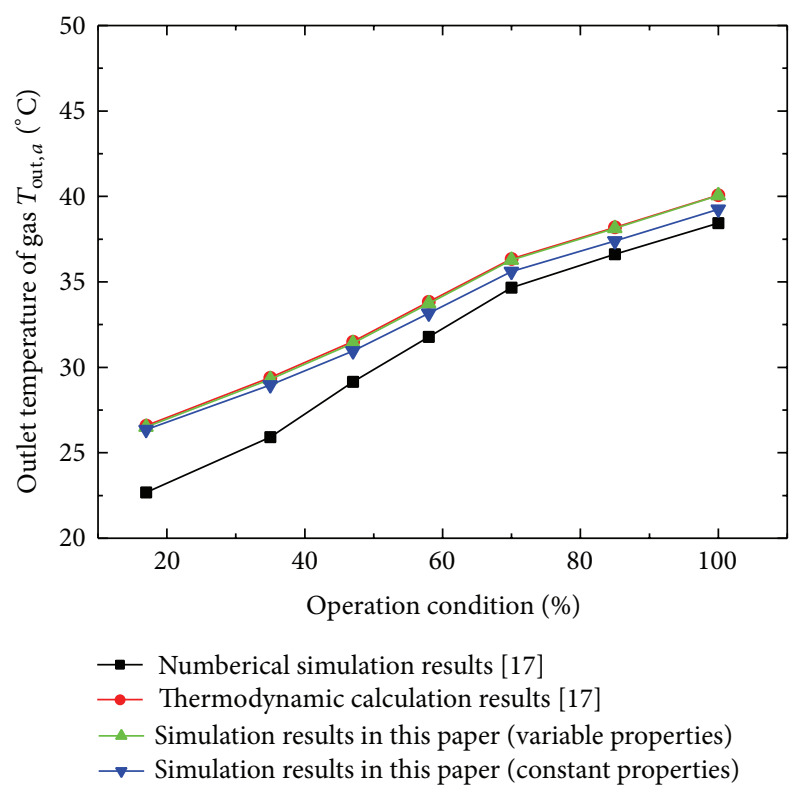

FIGURE 5: Comparisons of simulation outlet temperature of gas with the results reported in literature [17].

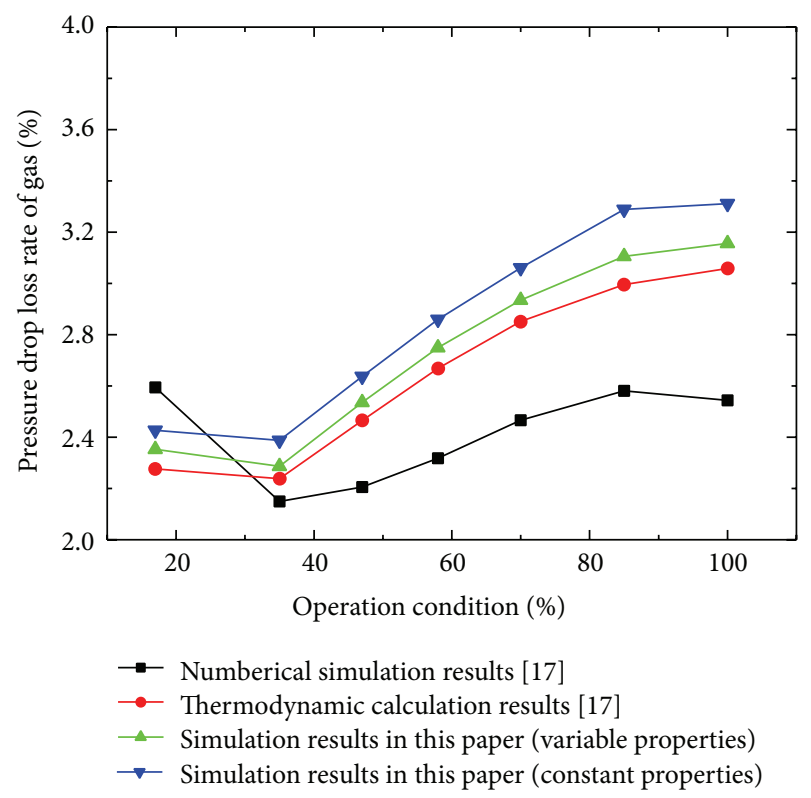

FIGURE 6: Comparisons of simulation pressure drop loss rate of gas with the results reported in literature [17].

the thermodynamic performance of gas turbine. In addition, a careful inspection of Figures 8-10 reveals that intercooler made of copper or aluminum has the better heat transfer performance than that made of copper-nickel alloy. And the intercooler made of copper has the best heat transfer performance since it has the highest thermal conductivity. However, the dynamic response time of intercooler made of aluminum is the shortest as compared with the intercooler made of the other types of materials. This is due to the fact that aluminum has the lowest density. The larger the value

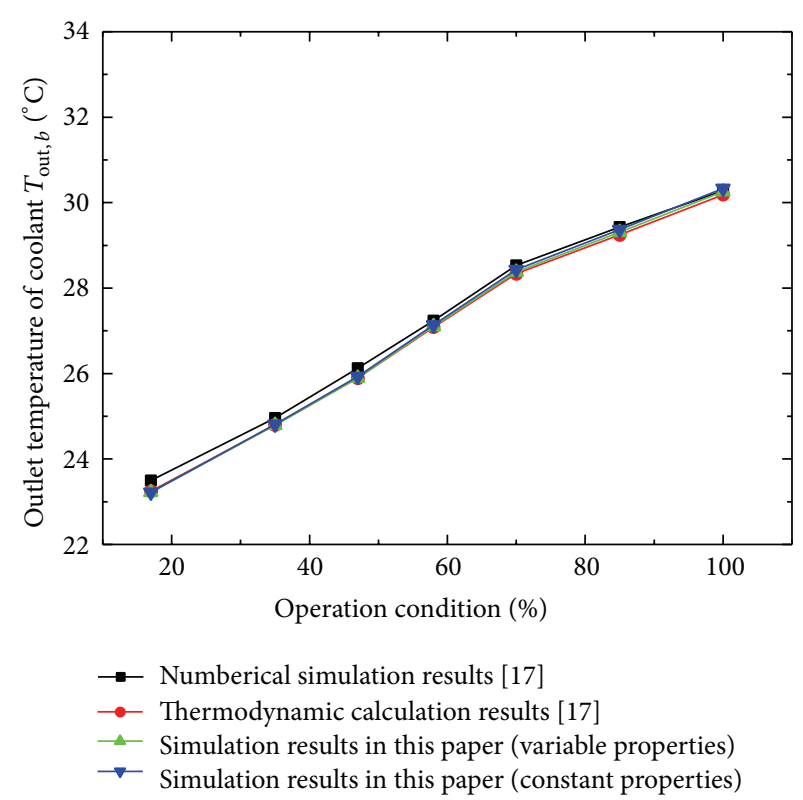

FIGURE 7: Comparisons of simulation outlet temperature of coolant with the results reported in literature [17].

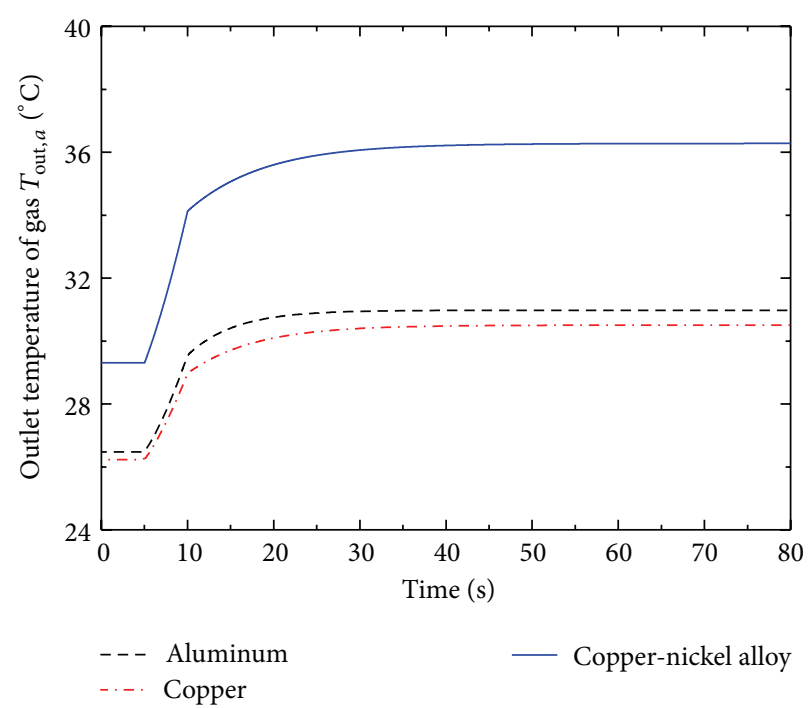

FIGURE 8: Dynamic response curve of the outlet temperature of gas with different materials.

of density is, the longer the dynamic response time of the intercooler will be. From Table 3, it can be seen that the three materials, ordered by decreasing density, are (1) copper, (2) copper-nickel alloy, and (3) aluminum. These suggest that the weight of intercooler is the important factor on affecting the thermal inertia of intercooler, which is consistent with the result of the other literatures [16]. Additionally, the outlet pressure of gas is less affected by materials and there is no obvious flow time delay characteristic because gas has a higher velocity.

To sum up, material is a significant factor which affects the heat transfer and dynamic performance of intercooler. From 


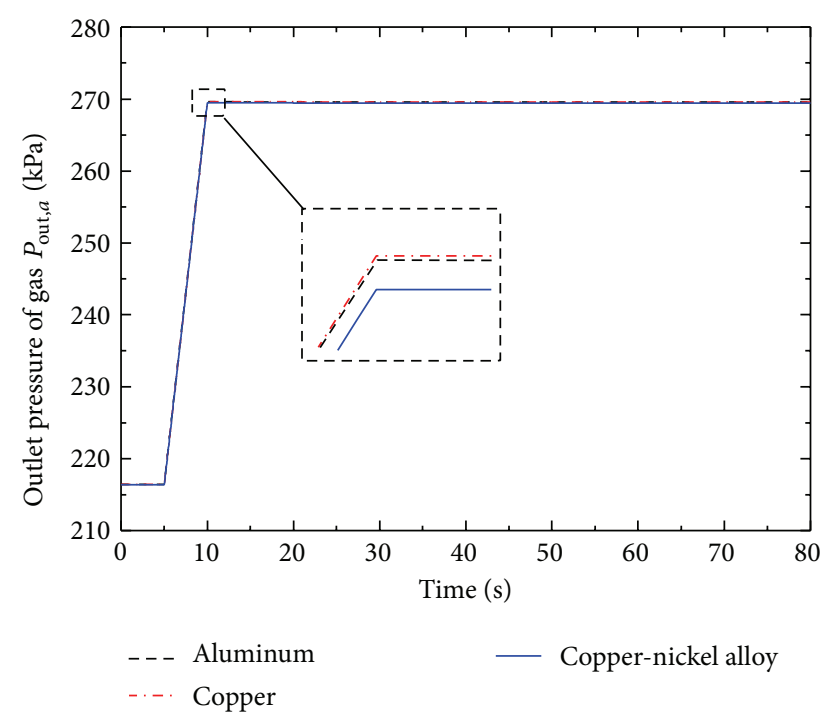

FIGURE 9: Dynamic response curve of the outlet pressure of gas with different materials.

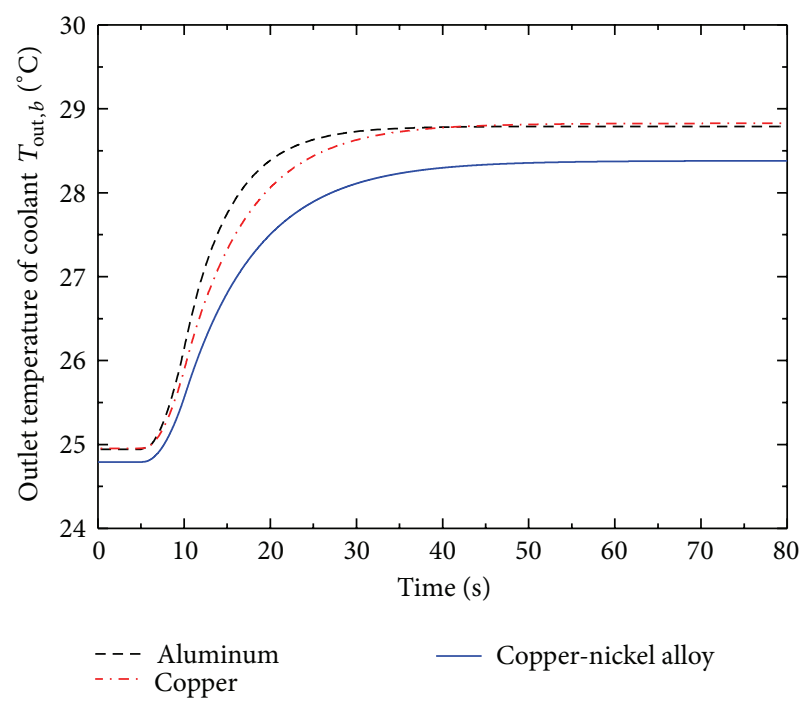

FIGURE 10: Dynamic response curve of the outlet temperature of coolant with different materials.

the point of view of heat transfer performance and dynamic time-delay characteristics, aluminum has a slightly better performance than the other materials. However, considering the application environment, copper-nickel alloy is often used as the material of intercooler because it has good anticorrosion and excellent strength.

3.3. Coolant Effects on Dynamic Performance. Although the copper-nickel alloy has good anticorrosion and excellent strength, its heat transfer performance is relatively poor and dynamic delay response time is longer than the other materials. Therefore, it is very important to improve the heat transfer and dynamic performance of intercooler from other aspects.
Coolant seems to be another crucial factor in determining the heat transfer and dynamic performance of intercooler. As the most common and cheap coolant, water freezes at a low temperature, which can lead to intercooler failure. In order to solve this problem, ethylene glycol mixed with water in different volume percentages is typically used to lower the aqueous freezing point of the heat transfer medium in the practical industrial applications [22]. Ethylene glycol and water (EG/water) can withstand low temperatures down to $-60^{\circ} \mathrm{C}$ [23]. However, it can cause an erosive action on the intercooler, which causes fouling and affects the heat transfer performance of intercooler. Besides, this fluid mixture is toxic so that it is a potential danger for staff.

In the following analysis, we are interested in investigating the effects of different coolants on dynamic performance of intercooler. Water and EG/water (50:50 by mass) are chosen as the coolant and the inlet temperature and mass flow of two coolants are assumed to be constant under different gas turbine operation conditions, which are $20^{\circ} \mathrm{C}$ and $200 \mathrm{~kg} / \mathrm{s}$, respectively. The properties of two coolants at different temperature are available in ASHRAE [24]. The intercooler is made of copper-nickel alloy. For the gas turbine, the operation condition linearly changes from $35 \%$ to $70 \%$ in 5 seconds and the related inlet operation parameters of gas are given in Table 2.

Figures 11, 12, and 13 show the dynamic response curve of the outlet temperature and pressure of gas and the outlet temperature of coolant with different coolants in the change of operation condition of gas turbine. From Figures 11-13, it is easy to see that the intercooler has better heat transfer performance and smaller thermal inertia when water is used as coolant. The outlet temperature and dynamic delay response time of gas obtained by using water as coolant can reduce about $3^{\circ} \mathrm{C}$ and 15 seconds, respectively, compared with those obtained by using EG/water as coolant. The main reason may come from the fact that water has higher heat capacity and thermal conductivity and lower viscosity than EG/water. In other words, the coolants with higher thermal conductivity and heat capacity but lower viscosity show better heat transfer performance and thermal inertia. Meanwhile, the results also show that the dynamic delay response time of gas is shorter than that of every coolant. This is due to the fact that coolants have higher heat capacity and thermal conductivity. Additionally, the outlet pressure of gas is less affected by coolants and there is no obvious flow time delay characteristic.

These findings suggest that all the applied conditions of coolants, corrosion resistant properties of materials, and the flow heat transfer performance requirements of intercooler should be considered when selecting the coolants for intercooler.

\section{Optimal Design of Intercooler Based on Simulated Annealing Algorithm}

The design of intercooler involves a large number of geometric and operating variables that need to meet the flow and heat transfer performance requirement under some 


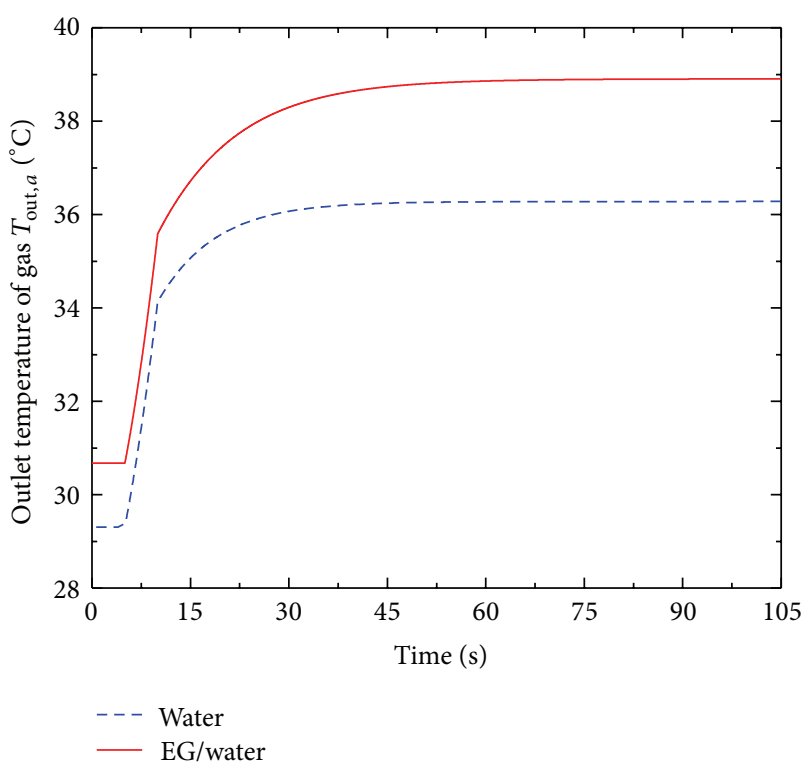

FIGURE 11: Dynamic response curve of the outlet temperature of gas with different coolants.

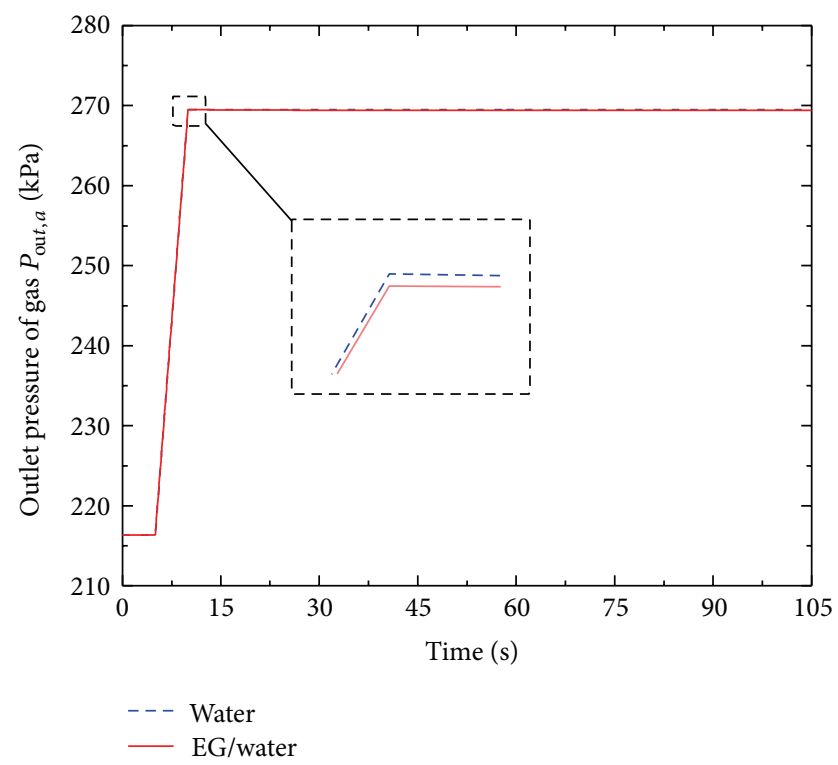

FIGURE 12: Dynamic response curve of the outlet pressure of gas with different materials.

constraints [15]. The conventional optimization methods become very cumbersome and laborious to solve the optimization problem. In recent times, some nontraditional probabilistic search algorithms, namely, genetic algorithm (GA) [25-27], particle swarm optimization (PSO) algorithm [28], and harmony search (HS) algorithm [20], have been applied to the optimization of various heat exchangers. Wang et al. [25] presented the GA for the optimization of microturbine recuperators from technical and economic standpoints and discussed the solution strategies under two different fitness functions. Their results showed that GA

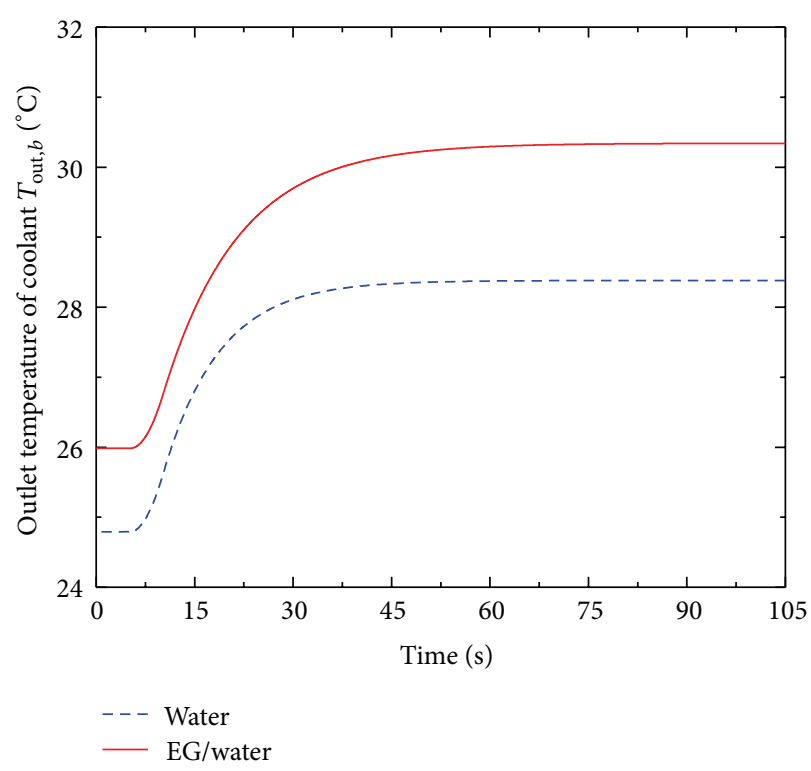

FIGURE 13: Dynamic response curve of the outlet temperature of coolant with different materials.

has good global search capability to realize the compact design of recuperators. However, GA is not very effective for the local search space problem. Compared with GA, PSO algorithm has the ability of memory. But PSO algorithm has a shortcoming of converging prematurely after getting trapped into some local optima and considers it to be the global optima. Besides, the acceleration constants and inertia weight should be given reasonably since they are employed to control the exploration abilities of the swarm and affect the convergence behavior. When PSO algorithm is applied to a multidimensional complex problem scenario, it becomes nearly impossible to get out from that local optima and reach out for the global optima due to some constraints. Moreover, the evolutionary algorithms, such as GA, PSO algorithm, and HS algorithm, cannot deal with the constraints directly and many constraint handling methods should be employed to help the optimization process [20].

As previously mentioned, it is a constraints optimization problem for the structure optimization design of intercooler. The penalty function method is often used to transfer constrained condition into unconstrained condition [20,26], which may affect the optimization results. As a stochastic optimization technique, simulated annealing algorithm was first put forward by Metropolis in 1953, and it was employed to seek an optimal combination by Kirkpatrick et al. until 1983 [29]. This algorithm simulates the thermodynamic process of slow cooling of molten metals to achieve the minimum function value in an optimization problem, so it has been widely used in solving sophisticated optimization problems [30]. Compared with GA and PSO algorithm, SA algorithm can hinder the premature convergence to the local optima and diverge the particles using its strong ability of local search. 


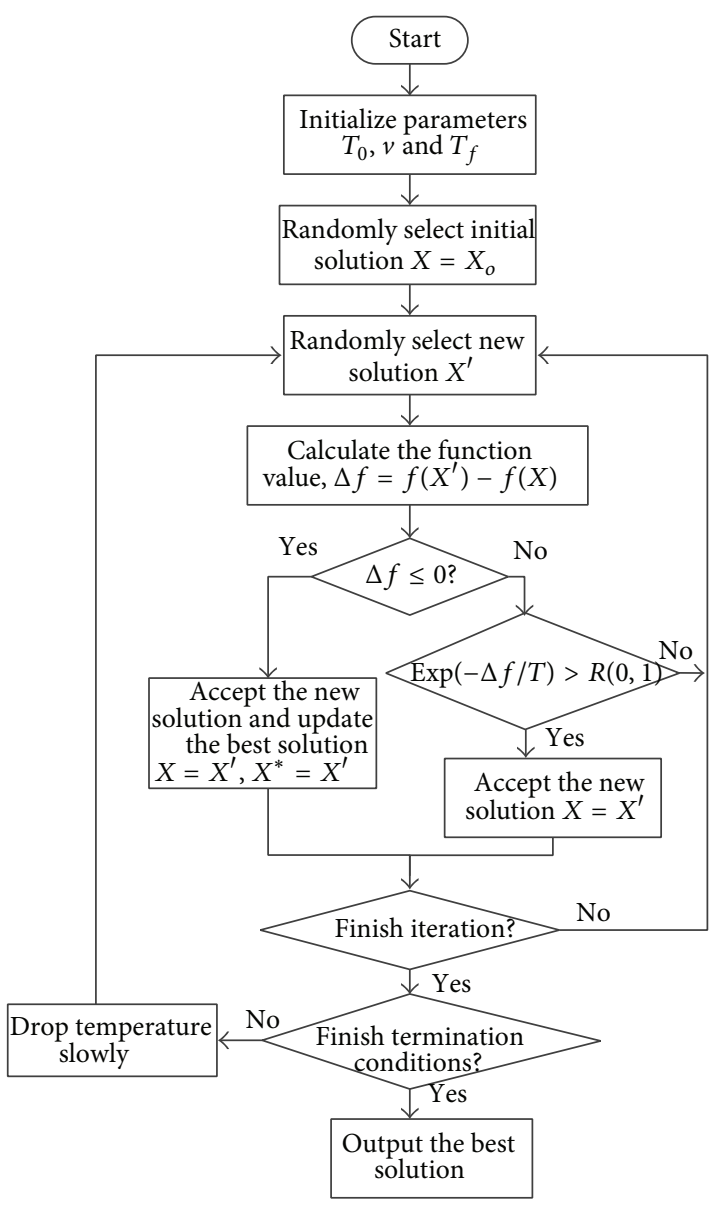

FIGURE 14: Flowchart of simulated annealing algorithm applied for the optimization of intercooler.

4.1. Simulated Annealing Algorithm. For the following optimization problem, the basic optimization process based on simulated annealing algorithm is shown in Figure 14:

$$
\begin{array}{ll}
\min & f(X) \quad X=\left[x_{1}, x_{2}, \ldots, x_{n}\right] \\
\text { s.t. } & \left\{\begin{array}{l}
g_{i}(X) \leq 0, \quad i=1,2, \ldots, m, \\
h_{j}(X)=0, \quad j=1,2, \ldots, l,
\end{array}\right.
\end{array}
$$

where $f(X)$ is the objective function. $g_{i}(X)$ and $h_{j}(X)$ are the constraint equations and equilibrium equations, respectively.

From Figure 14, we can see that simulated annealing algorithm mainly includes two circle processes, inner and outer circle processes. The purpose of the outer circle processes is to decrease annealing temperature. In every iteration of inner circle processes, the new solution is obtained and evaluated by the Metropolis criterion to determine whether the new solution will be accepted or not. The following shows the details of the basic optimization processes.

Step 1. Set initial temperature $T=T_{0}\left(T_{0}>0\right)$, cooling rate $v$, and final temperature $T_{f}$.

Step 2. Randomly select initial solution $X$ and the approximation of the optimal solution $X^{*}$ from all possible solutions, $X=X^{*}=X_{0}$.
Step 3. Randomly select disturbance to obtain the new solution $X^{\prime}$ from the sets of all possible neighbors of $X$.

Step 4. Calculate the function value $f(X)$ and $f\left(X^{\prime}\right)$ by objective function, respectively. $\Delta f=f\left(X^{\prime}\right)-f(X)$.

Step 5. If $\Delta f \leq 0$, then the new solution is accepted and the approximation of the optimal solution is updated, $X=$ $X^{\prime}, X^{*}=X^{\prime}$.

Step 6. If $\Delta f>0$, randomly select $R$ from uniform distribution on the interval $(0,1)$. If $P(\Delta f)=\exp (-\Delta f / T)>$ $R(0,1)$, then the new solution is accepted but it is a worse solution, $X=X^{\prime}$. Or else, the current solution remains unchanged.

Step 7. Repeat the above Steps 3-6, until loop iteration steps meet the requirements.

Step 8. Check termination criterion and output the optimal solution.

Simulated annealing algorithm uses the cooling process and the Metropolis algorithm to control the search process, so this algorithm can leap from the local minimum during the search and handle any type of variable easily, including noncontinuous functions and nondifferential functions [29].

4.2. Objective Function, Optimization Variables, and Constraints. The results reported in literature [16] showed that the weight of intercooler is an important factor to affect its thermal inertia. With the increase of the weight of intercooler, the thermal inertia increases rapidly. Therefore, the total weight of intercooler is selected as the optimal objective function in this study:

$$
\min M_{w}=\rho_{w}\left(V-V_{a}-V_{b}\right) .
$$

When putting all the relevant values, the above equation can be simplified and expressed as

$$
\begin{aligned}
\min M_{w}=\rho_{w}[ & L 1 L 2\left(N_{a} H_{a}+N_{b}\left(H_{b}+2 \delta_{p}\right)+2 \delta_{\mathrm{sp}}\right) \\
& -\frac{\left(H_{a}-t_{f, a}\right)\left(S_{f, a}-t_{f, a}\right) L 1 N_{a}\left(L 2-2 \delta_{s}\right)}{S_{f, a}} \\
& \left.-\frac{\left(H_{b}-t_{f, b}\right)\left(S_{f, b}-t_{f, b}\right) L 1 N_{b}\left(L 2-2 \delta_{s}\right)}{S_{f, b}}\right] .
\end{aligned}
$$

Considering the basic assumptions mentioned above, the plate pitches for the two sides, fin pitch, fin thickness, intercooler length, intercooler width, and numbers of fin layers for gas side are taken as the optimization variables in 
TABLE 4: Variation ranges of design parameters and performance constraints of intercooler.

\begin{tabular}{lcc}
\hline Parameters & Minimum & Maximum \\
\hline Number of gas side fin layers, $N_{a}$ & 30 & 40 \\
Fin pitch of gas side, $S_{f, a}(\mathrm{~m})$ & $1.5 \times 10^{-3}$ & $3 \times 10^{-3}$ \\
Plate pitch of gas side, $H_{a}(\mathrm{~m})$ & $4 \times 10^{-3}$ & $7 \times 10^{-3}$ \\
Fin thickness of gas side, $t_{f, a}(\mathrm{~m})$ & $1.5 \times 10^{-4}$ & $3 \times 10^{-4}$ \\
Plate pitch of coolant side, $H_{b}(\mathrm{~m})$ & $2 \times 10^{-3}$ & $4.5 \times 10^{-3}$ \\
Intercooler length, $L 1(\mathrm{~m})$ & 0.31 & 0.38 \\
Intercooler width, $L 2(\mathrm{~m})$ & 0.400 & 0.500 \\
Effectiveness, $\varepsilon(\%)$ & 85 & \\
Pressure drop loss rate of gas side, $\gamma_{a}(\%)$ & & 5 \\
\hline
\end{tabular}

this study. All the above optimization variables are considered as structural constraints, which are expressed as

$$
\text { s.t. }\left\{\begin{array}{l}
g_{1}(X) \Longrightarrow H_{a, \min } \leq H_{a} \leq H_{a, \max } \\
g_{2}(X) \Longrightarrow H_{b, \min } \leq H_{b} \leq H_{b, \max } \\
g_{3}(X) \Longrightarrow S_{f, a, \min } \leq S_{f, a} \leq S_{f, a, \max } \\
g_{4}(X) \Longrightarrow t_{f, a, \min } \leq t_{f, a} \leq t_{f, a, \max } \\
g_{5}(X) \Longrightarrow L 1_{\min } \leq L 1 \leq L 1_{\max } \\
g_{6}(X) \Longrightarrow L 2_{\min } \leq L 2 \leq L 2_{\max } \\
g_{7}(X) \Longrightarrow N_{a, \min } \leq N_{a} \leq N_{a, \max }
\end{array}\right.
$$

In order to achieve the design requirements, the heat transfer efficiency required of intercooler and the pressure drop loss rate of gas are considered as the performance constraints, which can be given as follows:

$$
\text { s.t. }\left\{\begin{array}{l}
g_{8}(X) \Longrightarrow \varepsilon \geq \varepsilon_{\min }, \\
g_{9}(X) \Longrightarrow \gamma_{a} \leq \gamma_{a, \max } .
\end{array}\right.
$$

4.3. Optimal Design Results of Intercooler. This section explores the use of simulated annealing (SA) algorithm for structure optimization of intercooler and discusses the effects of structure optimization on dynamic performance of intercooler. The intercooler is made of copper-nickel alloy. Water is chosen as the coolant and the inlet temperature and mass flow of two coolants are assumed to be constant under different gas turbine operation conditions, which are $20^{\circ} \mathrm{C}$ and $200 \mathrm{~kg} / \mathrm{s}$, respectively. Gas turbine operates in a $100 \%$ condition.

In this study, the seven design variables such as the plate pitches for the two sides, fin pitch, fin thickness, intercooler length, intercooler width, and numbers of fin layers for gas side are selected as the optimization variables. All variables are continuous except the number of gas side layers. The other structural parameters of intercooler such as plate thickness, seal thickness, and side plate thickness are considered to be constant as listed in Table 1 and are not to be optimized. The variation ranges of the design variables and performance constraints of intercooler have been mentioned in Table 4 .

Figure 15 shows the effectiveness convergence diagram as objective function. A significant decrease in the objective function has been observed in the beginning of the evaluation process after 100 iterations. After approximate 6000 iterations, the changes in the objective function become

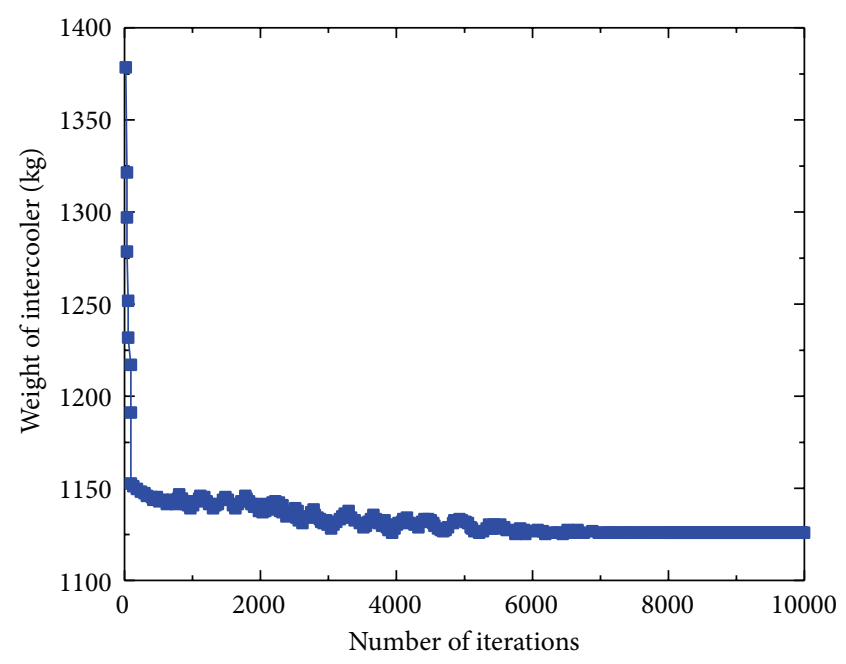

FIGURE 15: Evolution process for minimum weight based on simulated annealing algorithm.

TABLE 5: The structure comparisons of preliminary design and simulated annealing algorithm.

\begin{tabular}{lcc}
\hline Parameters & $\begin{array}{c}\text { Preliminary } \\
\text { design }\end{array}$ & $\begin{array}{c}\text { Optimal } \\
\text { design }\end{array}$ \\
\hline Number of gas side fin layers, $N_{a}$ & 36 & 37 \\
Fin pitch of gas side, $S_{f, a}(\mathrm{~m})$ & $1.4 \times 10^{-3}$ & $1.1 \times 10^{-3}$ \\
Plate pitch of gas side, $H_{a}(\mathrm{~m})$ & $6.2 \times 10^{-3}$ & $6.3 \times 10^{-3}$ \\
Fin thickness of gas side, $t_{f, a}(\mathrm{~m})$ & $2 \times 10^{-4}$ & $1.5 \times 10^{-4}$ \\
Plate pitch of coolant side, $H_{b}(\mathrm{~m})$ & $3 \times 10^{-3}$ & $2.1 \times 10^{-3}$ \\
Intercooler length, $L 1(\mathrm{~m})$ & 0.350 & 0.3222 \\
Intercooler width, $L 2(\mathrm{~m})$ & 0.4266 & 0.4045 \\
\hline
\end{tabular}

TABLE 6: The performance comparisons of preliminary design and simulated annealing algorithm.

\begin{tabular}{lcc}
\hline Parameters & $\begin{array}{c}\text { Preliminary } \\
\text { design }\end{array}$ & $\begin{array}{c}\text { Optimal } \\
\text { design }\end{array}$ \\
\hline Effectiveness, $\varepsilon(\%)$ & 84.97 & 87.04 \\
Pressure drop loss rate of gas side, $\gamma_{a}(\%)$ & 3.17 & 3.62 \\
Weight, $M_{w}(\mathrm{~kg})$ & 1391.45 & 1139.87 \\
\hline
\end{tabular}

relatively low. Finally, the minimum weight of intercooler is found after 7000 iterations with the value of $1139.87 \mathrm{~kg}$. Tables 5 and 6 show the preliminary design of intercooler and optimum structure which are obtained from simulated annealing algorithm. The increment of $2.07 \%$ has been observed in efficiency of intercooler by optimization method in comparison with preliminary design. Besides, the weight of intercooler has decreased from $1391.45 \mathrm{~kg}$ to $1139.87 \mathrm{~kg}$ while the pressure drop loss rate of gas side has increased from $3.17 \%$ to $3.62 \%$.

The dynamic response curve of the outlet temperature and pressure of gas and outlet temperature of coolant with different intercoolers (preliminary design and optimum structure) in the linear change of operation condition of gas 


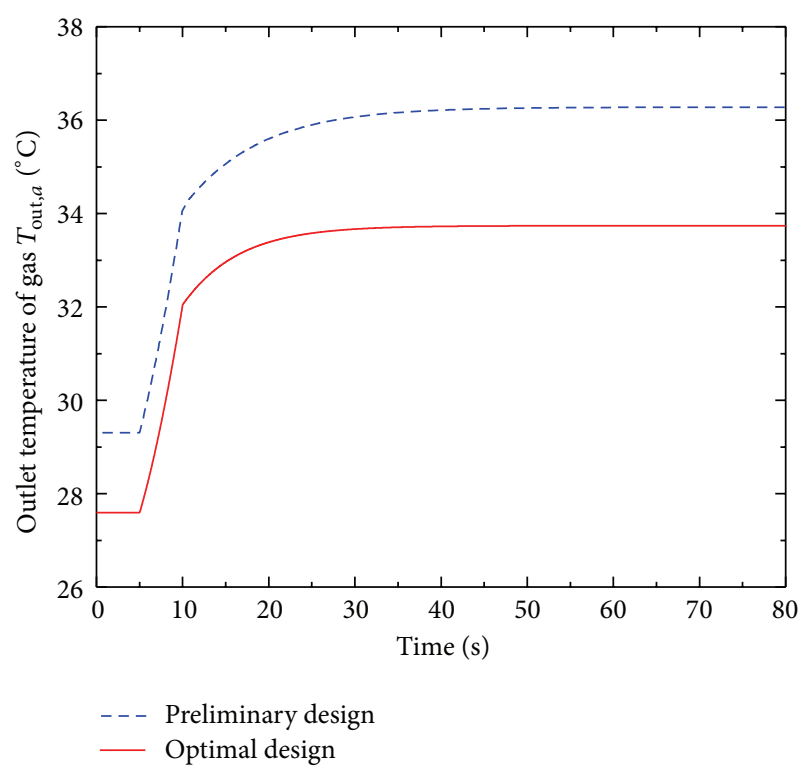

FIGURE 16: Dynamic response curve of the outlet temperature of gas with different intercoolers.

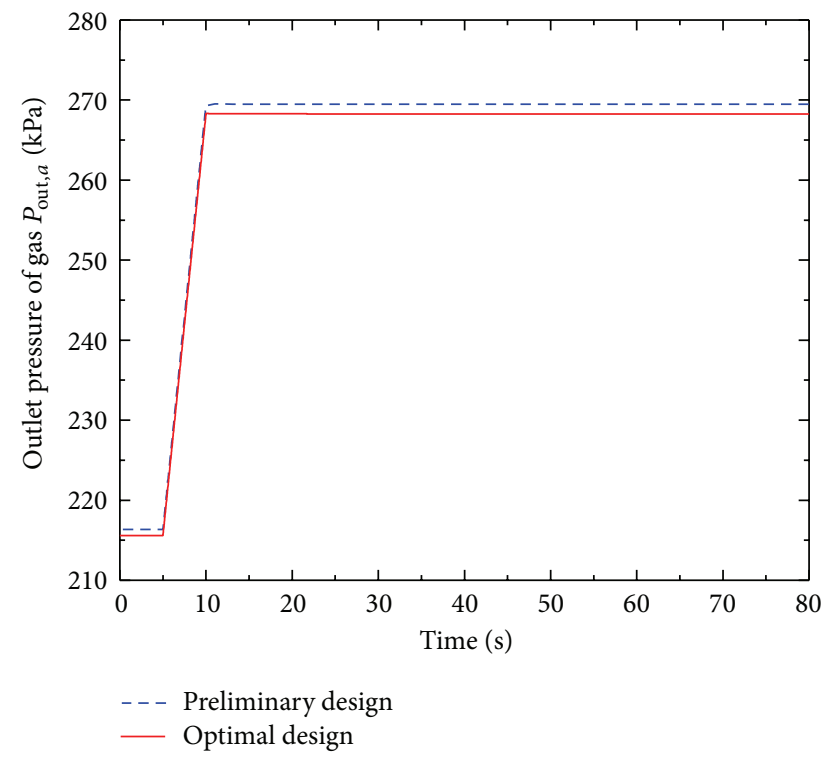

FIGURE 17: Dynamic response curve of the outlet pressure of gas with different intercoolers.

turbine from $35 \%$ to $70 \%$ in 5 seconds are shown in Figures 16,17 , and 18. From Figures 16-18, it is clear that the intercooler optimized by simulated annealing algorithm has better heat transfer performance and smaller thermal inertia. The outlet temperature of gas obtained by simulated annealing algorithm can reduce about $3^{\circ} \mathrm{C}$ compared with that obtained by preliminary design. The dynamic delay response times of gas and coolant sides of preliminary intercooler are 11.5 seconds and 20 seconds longer than those obtained by the simulated annealing algorithm. These findings suggest that optimal design based on artificial intelligence algorithm is available and necessary to realize the high compact design of

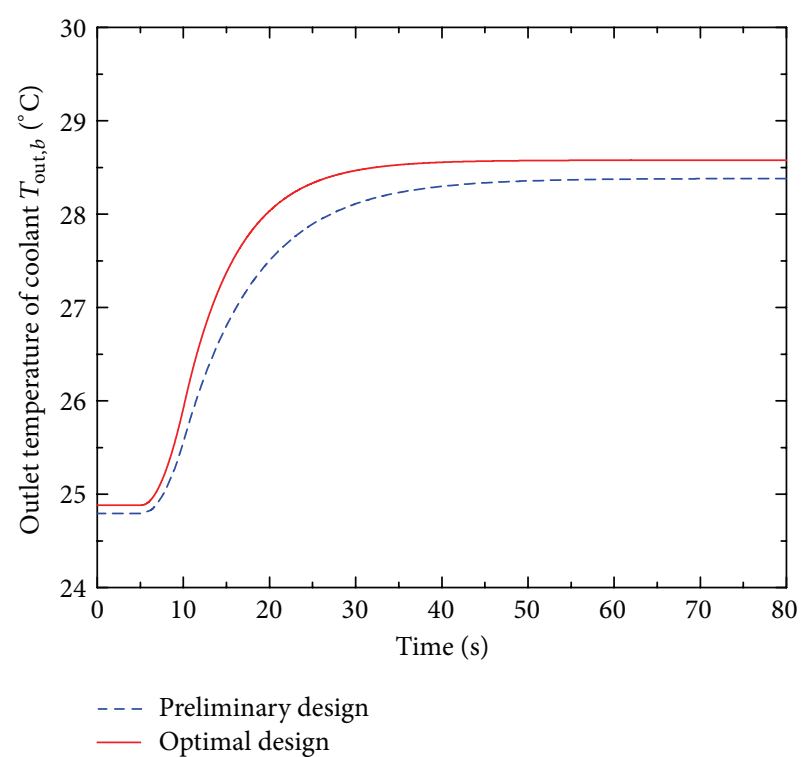

FIgURE 18: Dynamic response curve of the outlet temperature of coolant with different intercoolers.

intercooler, which can further affect the overall performance of intercooled cycle marine gas turbine.

\section{Conclusions}

This study studied the dynamic time-delay characteristics of marine gas turbine intercooler and showed the successful usage of the simulated annealing (SA) algorithm in the optimal design of intercooler. On the basis of the work presented in this study, the following conclusions could be made. A generalized simulation model was developed to carry out the dynamic performance analysis of intercooler based on the effectiveness-number of transfer units and lumped parameter method. The analytical results of an example showed that the simulation model (variable properties) established in this study was correct and feasible. The effects of substrate materials and coolants on the dynamic timedelay characteristics of intercooler were analyzed in detail. The results showed that both material and coolant were the significant factors that affected the heat transfer and dynamic performance of intercooler. For all materials and coolants, gas side had a slightly smaller thermal inertia than liquid side. When other conditions were constant, better thermal performance and smaller thermal inertia were noted for the materials with higher thermal conductivity and lower density than that for the material with lower thermal conductivity and higher density. Besides, the coolant with higher thermal conductivity and specific heat but lower viscosity was beneficial to improve the heat transfer performance and thermal conductivity of intercooler. However, the outlet pressure of gas was less affected by materials and coolants, and there was no obvious flow time-delay characteristic. The present study demonstrated successful application of simulated annealing technique for the structure optimization of intercooler considering minimum weight as objective 
functions. The improvement of heat transfer and dynamic performance was observed for intercooler obtained by using simulated annealing algorithm compared with preliminarily design, showing the improvement potential of the artificial intelligent technique for intercooler optimization.

\section{Notation}

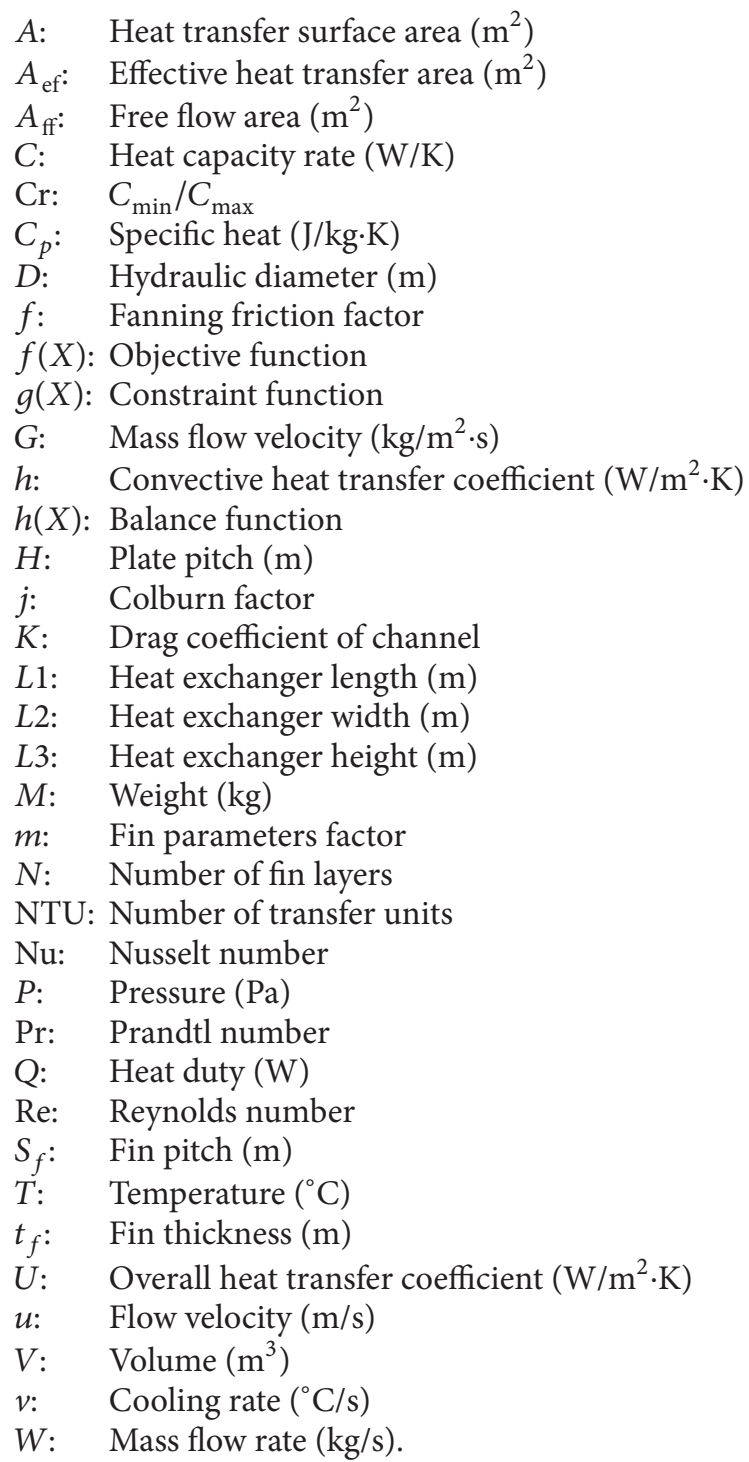

\section{Greek Letters}

$\eta_{\mathrm{ef}}:$ Effective heat transfer surface efficiency

$\eta_{f}$ : Heat transfer efficiency of fin

$\delta$ : Thickness (m)

$\lambda$ : Thermal conductivity $(\mathrm{W} / \mathrm{m} \cdot \mathrm{K})$

$\mu$ : Viscosity $\left(\mathrm{N} / \mathrm{m}^{2} \cdot \mathrm{s}\right)$

$\rho:$ Density $\left(\mathrm{kg} / \mathrm{m}^{3}\right)$

$\varepsilon: \quad$ Effectiveness

$\alpha$ : The ratio of channel free flow area and cross-sectional area

$\gamma$ : $\quad$ Pressure drop loss rate.

\author{
Subscripts \\ a: Gas \\ $b$ : Coolant \\ p: Plate \\ $s: \quad$ Seal \\ sp: Side plate \\ $w$ : Wall \\ in: Inlet \\ out: Outlet \\ max: Maximum \\ min: Minimum.
}

\section{Conflict of Interests}

The authors declared that there is no conflict of interests regarding the publication of this paper.

\section{References}

[1] X. Y. Wen and D. M. Xiao, "Feasibility study of an intercooledcycle marine gas turbine," Journal of Engineering for Gas Turbines and Power, vol. 130, no. 2, Article ID 022201, 2008.

[2] X. Y. Wen and D. M. Xiao, "A new concept concerning the development of high-power marine gas turbines," Ship Science and Technology, vol. 29, no. 4, pp. 17-21, 2007 (Chinese).

[3] S. B. Shepard, T. L. Bowen, and J. M. Chiprich, "Design and development of the WR-21 intercooled recuperated (ICR) marine gas turbine," Journal of Engineering for Gas Turbines and Power, vol. 117, no. 3, pp. 557-562, 1995.

[4] S. Y. Li, Z. T. Wang, J. Q. Wang, and P. P. Luo, "Simulation study on fuel supply rate curve of marine inter-cooled gas turbine," Ship Engineering, vol. 32, no. 5, pp. 15-18, 2010 (Chinese).

[5] Y. L. Ying, Y. P. Cao, and S. Y. Li, "Research on fuel supply rate of marine intercooled-cycle engine based on simulation experiment," International Journal of Computer Applications in Technology, vol. 47, no. 4, pp. 212-221, 2013.

[6] Y. L. Ying, Y. P. Cao, S. Y. Li, and Z. T. Wang, "Study on flow parameters optimisation for marine gas turbine intercooler system based on simulation experiment," International Journal of Computer Applications in Technology, vol. 47, no. 1, pp. 56-67, 2013.

[7] W. H. Wang, L. G. Chen, and F. R. Sun, "Power optimization of a real closed intercooled regenerated gas turbine cycle," Chinese Journal of Mechanical Engineering, vol. 41, no. 4, pp. 55-58, 2005.

[8] W. H. Wang, L. G. Chen, F. R. Sun, and C. Wu, "Performance optimisation of open cycle intercooled gas turbine power plant with pressure drop irreversibilities," Journal of the Energy Institute, vol. 81, no. 1, pp. 31-37, 2008.

[9] W. H. Wang, L. G. Chen, and F. R. Sun, "Thermodynamic optimization of a triple-shaft open intercooled, recuperated gas turbine cycle. Part 1: description and modeling," International Journal of Low-Carbon Technologies, 2013.

[10] W. H. Wang, L. G. Chen, and F. R. Sun, “Thermodynamic optimization of a triple-shaft open intercooled, recuperated gas turbine cycle. Part 2: power and efficiency optimization," International Journal of Low-Carbon Technologies, 2013.

[11] C. Z. Wen and W. Dong, "Numerical simulation of heat transfer and fluid flow on marine gas turbine intercooler," Journal of Aerospace Power, vol. 25, no. 3, pp. 654-658, 2010. 
[12] W. Dong, C. Mao, J. J. Zhu, and Y. Chen, "Numerical and experimental analysis of inlet non-uniformity influence on intercooler performance," in Proceeding of the ASME Turbo Expo 2012: Turbine Technical Conference and Exposition (GT '12), pp. 349-357, Copenhagen, Denmark, June 2012.

[13] P. Gao and W. Dong, "Optimal analysis of flow parameters for marine gas turbine intercooler," Aeroengine, vol. 37, no. 4, pp. 29-32, 2011 (Chinese).

[14] Z. Li, H. B. Zhang, X. Y. Wen, and D. M. Xiao, "Numerical simulation of an intercooler for a complex-cycle Marine gas turbine," Journal of Engineering for Thermal Energy and Power, vol. 23, no. 2, pp. 148-152, 2008 (Chinese).

[15] X. Xiao, The optimization design, modeling and control of the gas turbine intercooler [M.S. thesis], Shanghai Jiao Tong University, 2013, (Chinese).

[16] S. K. Zhang, Simulation research on performance of marine intercooled cycle gas turbine [M.S. thesis], China Ship Research and Development Academy, 2012, (Chinese).

[17] C. Z. Wen, Design and study on intercooling heat exchanger of marine gas turbine [M.S. thesis], Shanghai Jiao Tong University, 2009, (Chinese).

[18] V. Gnielinski, "New equations for heat and mass transfer in turbulent pipe and channel flow (Neue Gleichungen für den Wärme-und den Stoffübergang in turbulent durchströmten Rohren und Kanälen)," Forschung im Ingenieurwesen, vol. 41, no. 1, pp. 8-16, 1975.

[19] H. Peng and X. Ling, "Optimal design approach for the plate-fin heat exchangers using neural networks cooperated with genetic algorithms," Applied Thermal Engineering, vol. 28, no. 5-6, pp. 642-650, 2008

[20] M. Yousefi, R. Enayatifar, A. N. Darus, and A. H. Abdullah, "Optimization of plate-fin heat exchangers by an improved harmony search algorithm," Applied Thermal Engineering, vol. 50, no. 1, pp. 877-885, 2013.

[21] S. H. Wang, Plate-Fin Heat Exchanger, Chemical Industry Press, Beijing, China, 1984 (Chinese).

[22] F. C. McQuiston, J. D. Parker, and J. D. Spitler, Heating Ventilating and Air Conditioning, John Wiley \& Sons, New York, NY, USA, 2000.

[23] P. K. Namburu, D. K. Das, K. M. Tanguturi, and R. S. Vajjha, "Numerical study of turbulent flow and heat transfer characteristics of nanofluids considering variable properties," International Journal of Thermal Sciences, vol. 48, no. 2, pp. 290302, 2009.

[24] ASHRAE Handbook Fundamentals, American Society of Heating, Refrigerating and Air-Conditioning Engineers, Atlanta, Ga, USA, 2005.

[25] Q. W. Wang, H. X. Liang, G. N. Xie, M. Zeng, L. Q. Luo, and Z. P. Feng, "Genetic algorithm optimization for primary surfaces recuperator of microturbine," Journal of Engineering for Gas Turbines and Power, vol. 129, no. 2, pp. 436-442, 2007.

[26] G. N. Xie, B. Sunden, and Q. W. Wang, "Optimization of compact heat exchangers by a genetic algorithm," Applied Thermal Engineering, vol. 28, no. 8-9, pp. 895-906, 2008.

[27] L. Gosselin, M. Tye-Gingras, and F. Mathieu-Potvin, "Review of utilization of genetic algorithms in heat transfer problems," International Journal of Heat and Mass Transfer, vol. 52, no. 910, pp. 2169-2188, 2009.

[28] R. V. Rao and V. K. Patel, "Thermodynamic optimization of cross flow plate-fin heat exchanger using a particle swarm optimization algorithm," International Journal of Thermal Sciences, vol. 49, no. 9, pp. 1712-1721, 2010.
[29] S. Kirkpatrick, J. Gelatt, and M. P. Vecchi, "Optimization by simulated annealing," American Association for the Advancement of Science: Science, vol. 220, no. 4598, pp. 671-680, 1983.

[30] J. M. Reneaume and N. Niclout, "Plate fin heat exchanger design using simulated annealing," Computer Aided Chemical Engineering, vol. 9, pp. 481-486, 2001. 


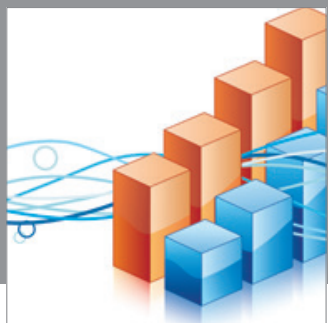

Advances in

Operations Research

mansans

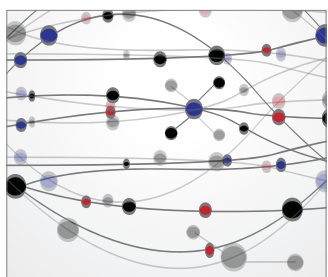

The Scientific World Journal
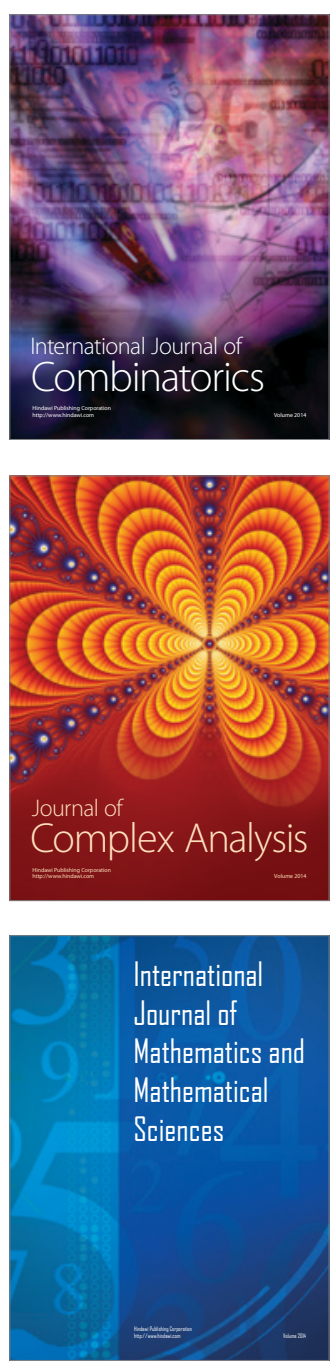
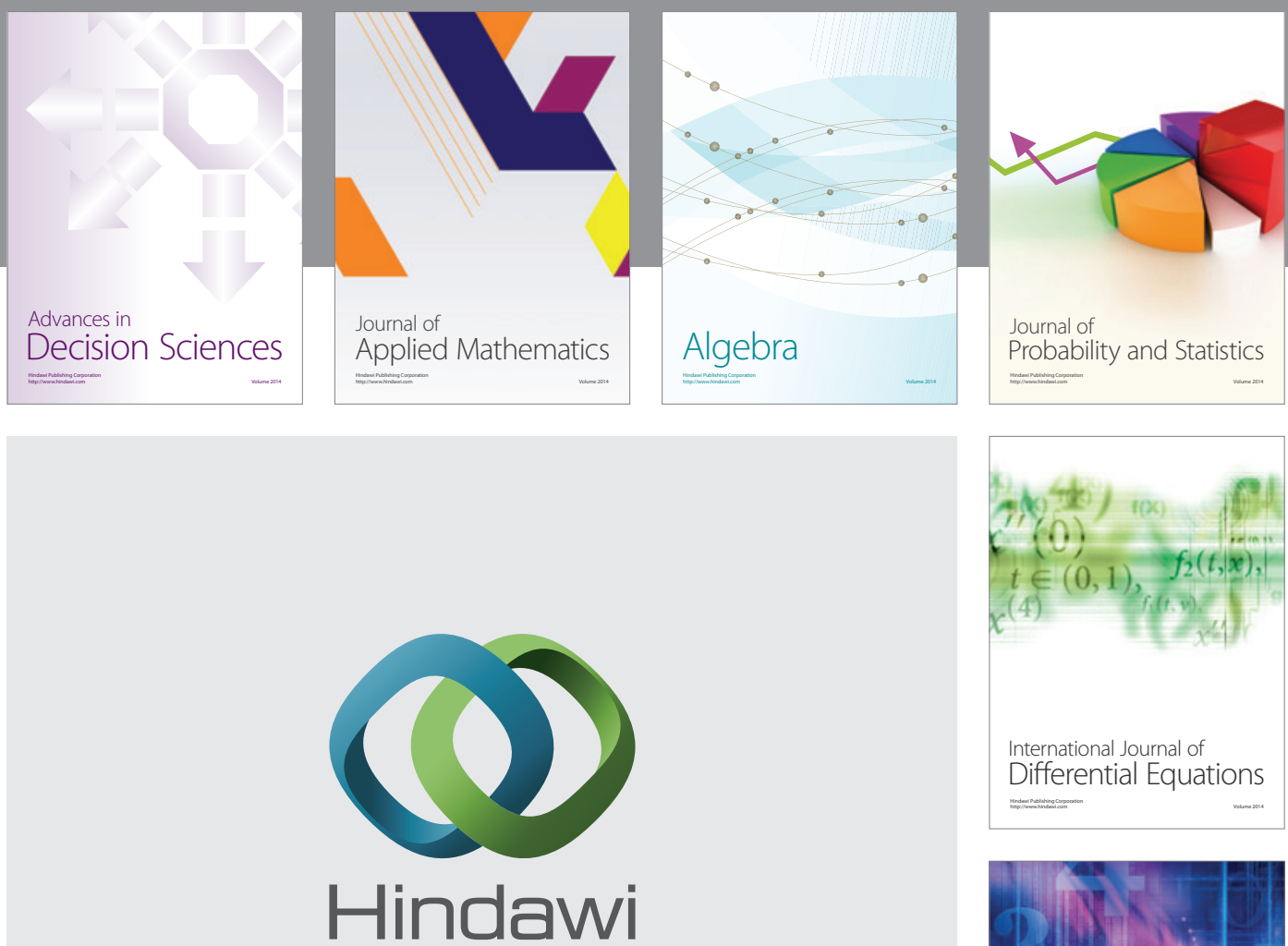

Submit your manuscripts at http://www.hindawi.com
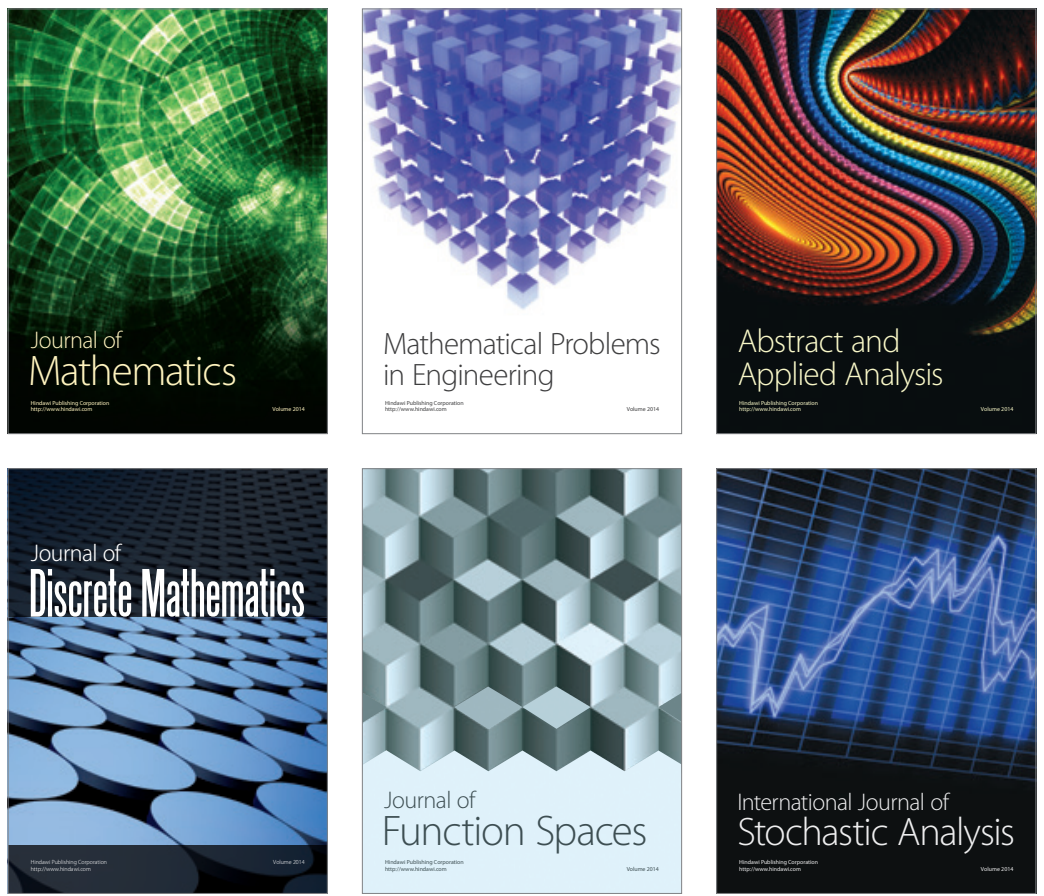

Journal of

Function Spaces

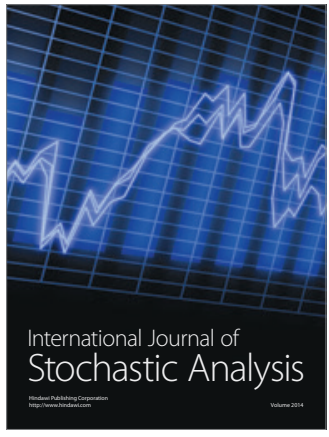

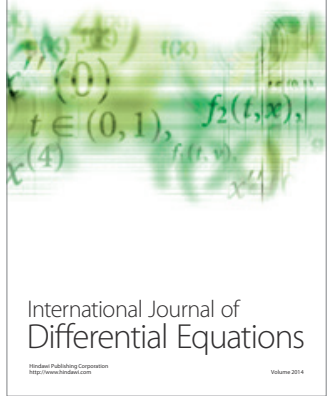
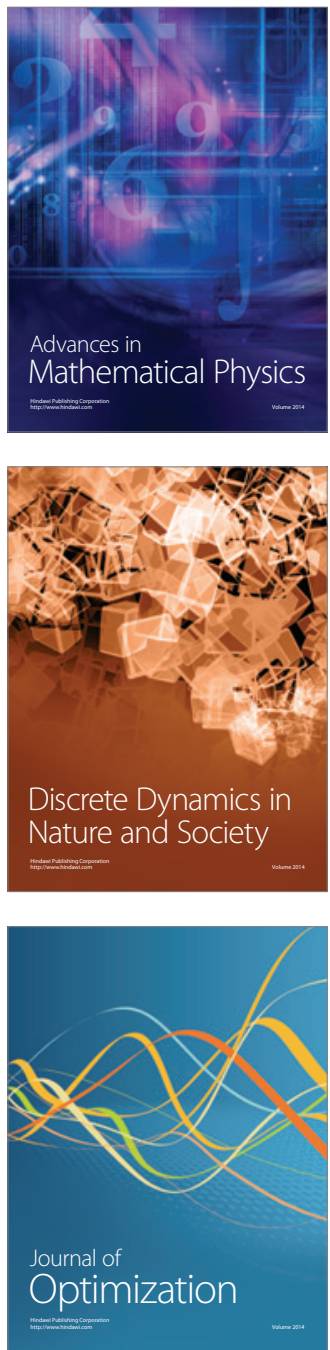